D

Dept of Pulmonology, Leiden University Medical Center, Leiden, The Netherlands.

\title{
How to write a response to the reviewers of your manuscript
}

\section{Doing science}

Cite as: Hiemstra PS. How to write a response to the reviewers of your manuscript. Breathe 2018; 14: 319-321.
Training programmes for scientists usually include modules on writing a scientific manuscript but rarely pay attention to dealing with comments from reviewers. The two main outcomes of the decision process following submission of a manuscript to a journal are: 1) the journal rejects your manuscript; or 2) the journal shows an interest provided that you adequately deal with the comments of the reviewers (major or minor revision). But how do you deal with these comments and how do you write a rebuttal letter in which you deal with these comments? Is the "reviewer always right" and if not, how do you indicate this? In this article, some suggestions are provided for writing a rebuttal letter based on personal experiences, including my experience as Section Editor for Basic Science for the European Respiratory Journal. Whereas this article is focussed on writing rebuttals to comments on submitted manuscripts, some of its content may also be useful for writing rebuttals for, for example, grant writing.

\section{How to write a response letter}

Consider the following: you have submitted a manuscript to a scientific journal, awaited the response from the journal and then you get an e-mail saying that it is nice but not acceptable in its present form. Is this good news or bad news? Actually, it is good news because the journal is apparently interested, and manuscripts rarely get accepted without any comments and subsequent revisions. So, now you have read the comments from the editor and the reviewers. What do you need to do next?

It is essential that you "sleep on it" before starting to write your rebuttal. You should carefully read the accompanying letter from the editor again to find out what they have highlighted in the reviewers' comments and whether any additional points have been raised. Next, read the reviewers' comments again carefully and check the issues raised by the reviewer with the manuscript you submitted. If you feel that none of the comments are worth making changes to your manuscript, you are most likely wrong. Read the comments again and sleep on it again.

The next thing to do is to carefully discuss the comments, a reply and the performance of additional experiments (if applicable) with your co-authors. After you have done that, decided whether and which additional experiments are needed, and you have performed and analysed these experiments, you can start to work on your reply to the comments: the rebuttal letter. Actually, it may be better to start earlier (the sooner the better) because that usually will increase the quality of your response. You can use the outline below to structure your work on the response.

When writing your reply or rebuttal, it is best to keep in mind that the better you structure this, the 
easier it is for the editor and reviewers to see what you have done. In addition, it helps you not to forget any issue raised by the journal. Here is a suggested outline for writing your response.

- Include a heading for every page with "Reply to the comments on manuscript [title of your manuscript] [manuscript ID number]" and "[your name] et al."

- Write an introduction to your response to the comments and summarise major changes you have made, and include this with this response or use it for a separate cover letter for the Editor. Do not forget to thank the editor and reviewers for their efforts.

- Organise the comments/questions from the editor and each reviewer and your response, for example, as follows.

1) Comment 1.1. (for comment 1 from reviewer 1) followed by a copy-paste of the comment or question, or a short summary of the point raised. If the reviewer's comments are not numbered, split the review into individual comments. You can use italics to highlight the comments from the reviewer.

2) Reply 1.1. (the reply to comment 1 from reviewer 1 ). This is why this is often called a point-by-point reply to the comments.

Prepare this document in the early phase to structure how you handle the comments. In the beginning you can use the "reply" space to simply type what you think the reply should be (e.g. with keywords) or whether additional experiments are (really) needed.

Here are some ground rules for the content of your reply.

- Discuss the comments in detail in advance with your co-authors and always send the proposed reply to the comments to your co-authors before submitting it. Carefully consider their comments and suggestions to improve the quality of your rebuttal letter, and remember that you answer on behalf of them.

- Carefully read the requirements from the journal for submitting a revised version (e.g. marked-up version)

- Realise that the reviewer has taken time to evaluate your manuscript and aims to help you to improve it (although it may sometimes appear otherwise). Be polite to the reviewer and editor, and do not be dismissive of their comments. Even if they appear to be making "stupid" remarks and you feel that "they have not understood your paper" or actually missed something. Please realise that this means that one of the key readers of your manuscript has not understood what you wanted to say, so you have to try harder. You can (and should) adapt the manuscript and answer by saying, "this has been clarified in the original manuscript on page $x$, but maybe we have not made this sufficiently clear. Therefore, we have now stressed this item on ..."

- Always be very specific in your response and address all points raised. A one-line reply is rarely sufficient. However, sometimes, in the case of, for example, an editorial comment or spelling error, you can answer "This has now been amended", "We agree" or "We apologise for this omission". If more than one reviewer has raised the same point, refer to this ("this point has been addressed in the reply to comment $x$ of reviewer $y$ "). Consider including additional information, data or figures for the reviewer that were not included in the manuscript if it helps you to make your point. If you cannot address a point raised by the reviewer, explain why. If you feel that a certain comment is outside the scope of your study, please explain this. If you disagree with the reviewer (yes, this may happen) and/or think that an additional experiment or analysis is not needed, explain why. Carefully consider also mentioning this in the Discussion, for example, in the paragraph with limitations, since readers may share the reviewer's opinion. Never claim to have made changes if you have not done so.

- If you have been asked to shorten some part of your manuscript, do so. You can even indicate by how much (words or percentage) you have shortened it.

- Make life easy for the reviewer and the editor. Always indicate where you have made a change in your manuscript in response to the question/ comments: "This is now addressed in the Discussion section of the revised manuscript on page $x$, line $y$." If appropriate, cite relevant references in your reply.

- The response that you write should be directed to the Editor and not to the Reviewers. You should write for instance "We agree with the reviewer ..."rather than "We agree with you". Always refer to the reviewer in third person.

\section{Concluding remarks and further reading}

We all know that rejection rates can be high, especially for high-profile journals. Always be aware that your resubmitted and revised manuscript may still be rejected. Writing a response or rebuttal letter, maybe performing additional experiments and revising your manuscript takes time, and there is usually also a deadline from the journal. Organising this process and making best use of the expertise of your co-authors (and the reviewers) increases your chances of being successful in getting your paper published. If your manuscript is rejected, either in its revised or original form, make sure to incorporate suggestions from the reviewers into the manuscript to make it better when you submit it to another journal. 
In addition to this contribution to Breathe, several websites provide information for writing response or rebuttal letters, including the "dos and don'ts" that come with writing such a letter. Suggestions can be found in the Further Reading section of this article.

\section{Acknowledgements}

I would like to thank Martin Kolb and James Chalmers, Chief Editor and Deputy Chief Editor of the European Respiratory Journal, for critical review of the manuscript and helpful suggestions.

\section{Conflict of interest}

P.S. Hiemstra reports receiving grants from Boehringer Ingelheim and Galapagos NV, outside the submitted work.

\section{References}

1. Sterk PJ, Rabe KF. The joy of writing a paper. Breathe 2008; 4 : 224-232.

2. Rusk N. How to write a rebuttal letter 2013. http://blogs. nature.com/methagora/2013/09/how-to-write-a-rebuttalletter.html. Date last updated: September 27, 2013.
3. Zinsky R, Skoczyński S, Jacinto T, et al. Peer reviewing. Breathe 2014; 10: 337-340. 